\title{
Image Case:Blood Malaria Parasites in a 20 Years Old Male Student Traveled to Sudan.
}

\author{
Tarik I Zaher ${ }^{1}$,Nahla Elgammal ${ }^{1}$, Samia E Etewa ${ }^{2}$,Taghrid M \\ Abdalla $^{1}$,Shereen M Ibrahem ${ }^{2}$,Ahmed Mansour ${ }^{3}$ \\ ${ }^{1}$ Tropical Medicine Department, Faculty of Medicine, Zagazig University, Egypt. \\ ${ }^{2}$ Parasitology Department, Faculty of Medicine, Zagazig University, Egypt.. \\ ${ }^{3}$ Haematology Unit ,Internal Medicine Department, Faculty of Medicine, Zagazig University, Egypt. \\ tareqzaher@gmail.com
}

A 20 years old male student presented with fever (reaching $40 \mathrm{C}$ ), rigors, nausea, vomiting, abdominal pain and severe weakness for three weeks. He gave a history of staying in Sudan for 14 months from where he arrived to Egypt about three months before admission to Haematology Unit ,Internal Medicine and Tropical Medicine Departments ,Zagazig University Hospitals.

He suffered from a similar attack about one year ago when he was in Sudan. The condition was diagnosed that time as malaria but the species was not defined. According to the patient, he was treated with lumifantrine artemether and improved.

By examination of the patient, he looked very ill with severe pallor, and marked splenomegaly. His investigations showed Pancytopenia with (RBC 2.400,000/ul and hemoglobin $8.6 \mathrm{gm} / \mathrm{dl}$ ), thrombocytopenia (platelets 100,000/ul) and leukopenia (3700/ul). ESR was high up to $110 / 1$ st hour and so CRP and LDH were also high. By ultrasound examination, the longitudinal diameter of his spleen was $18 \mathrm{~cm}$. Multiple blood films were done and ring forms and gametocytes of Plasmodium falciparum were visualized. Diagnosis of Malaria infection was established and the species was defined as Plasmodium falciparum (figure- 1).

The patient received full course of artemetherlumefantrine $(20 / 120 \mathrm{mg} /$ tablet) where he was given 6 doses, 4 tablets each. This course was followed by a course of doxycycline 100 mg capsule(twice per day)completed for one month(to avoid recrudescence). The patient showed marked progressive clinical and laboratory improvement. His splenomegaly improved almost to the normal longitudinal diameter $(13 \mathrm{~cm})$. Complete recovery was obtained after follow up for 3 monthes.

Malaria in Egypt is most probably imported[1] as it is about to be eradicated except re- emerged small outbreak occurred in a village in Aswan in year 2014 [2] and small endemic focus in Elfayoum Governorate[3] .

Ethical consideration: Consent was obtained from the case. All the information gathered from the patient was handled confidentially, and it was used only for research purpose.

Funding: None.

Conflict of interest: There is no conflict of interest.

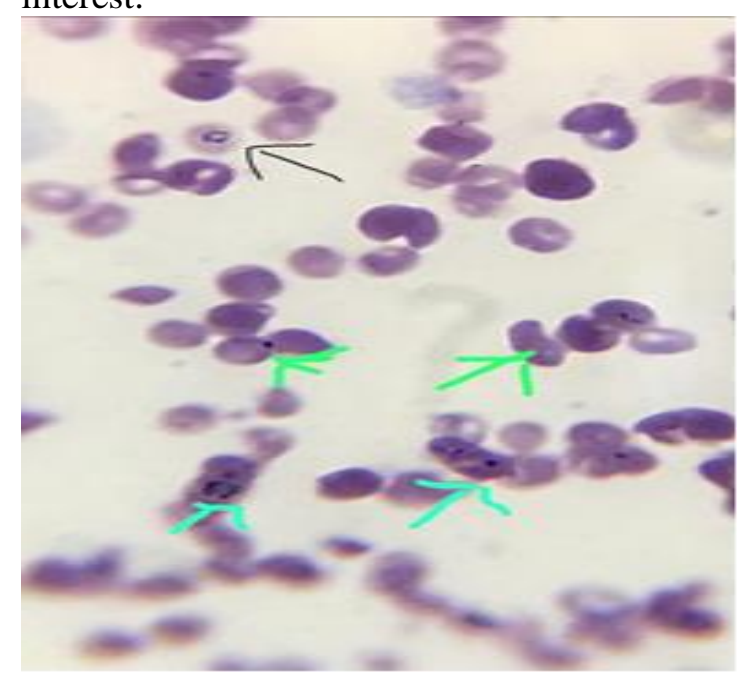

Figure- 1: Ring forms and gametocytes of Plasmodium falciparum.

\section{REFERENCES:}

1.Zaher TI; Elgammal NE; Mohamed D. Case 12011: A 60 years Old Male with Coma and Fever with Recent Travel to South Sudan Afro-Egypt J Infect Endem Dis 2011;1 (2):68-71.

2.Mahmoud DM, Hussein HM, El Gozamy BMR, Thabet HS, Hassan MA, Meselhey RA. Screening of Plasmodium parasite in vectors and humans in three villages in Aswan Governorate, Egypt. J Parasit Dis. 2019 ;43(1):158-163.

3.Kamel MM, Attia SS, Emam GD, Al Sherbiny NA. The Validity of Rapid Malaria Test and Microscopy in Detecting Malaria in a Preelimination Region of Egypt.Scientifica (Cairo). 2016;2016:4048032. 